BNL - 66960

\title{
Progress on Stella Experiment
}

W.D. Kimura, L.P. Campbell, S.C. Gottschalk, D.C. Quimby, K.E. Robinson, L.C. Steinhauer STI Optronics, Inc.

Bellevue, WA

M. Babzien, I. Ben-Zvi, J.C. Gallardo, K.P. Kusche, I.V. Pogorelsky, J. Skaritka,

A. van Steenbergen and V. Yakimenko

Brookhaven National Laboratory

Upton, NY

D.B. Cline, P. He, and Y. Liu

UCLA

Los Angeles, CA

R.B. Fiorito

Catholic University of America

Washington, DC

R.H. Pantell

Stanford University

Stanford, CA

D.W. Rule

Naval Surface Warfare Center

West Bethesda, MD

J. Sandweiss

Yale University

New Haven, CT

March 1999

\section{National Synchrotron Light Source}

Brookhaven National Laboratory

Operated by

Brookhaven Science Associates

Upton, NY 11973

Under Contract with the United States Department of Energy

Contract Number DE-AC02-98CH10886 


\section{DISCLAIMER}

This report was prepared as an account of work sponsored by an agency of the United States Government. Neither the United States Government nor any agency thereof, nor any of their employees, nor any of their contractors, subcontractors or their employees, makes any warranty, express or implied, or assumes any legal liability or responsibility for the accuracy, completeness, or any third party's use or the results of such use of any information, apparatus, product, or process disclosed, or represents that its use would not infringe privately owned rights. Reference herein to any specific commercial product, process, or service by trade name, trademark, manufacturer, or otherwise, does not necessarily constitute or imply its endorsement, recommendation, or favoring by the United States Government or any agency thereof or its contractors or subcontractors. The views and opinions of authors expressed herein do not necessarily state or reflect those of the United States Government or any agency thereof. 


\title{
PROGRESS ON STELLA EXPERIMENT ${ }^{*}$
}

\author{
W. D. Kimura, ${ }^{\#}$ L. P. Campbell, S. C. Gottschalk, D. C. Quimby, K. E. Robinson, L. C. Steinhauer, \\ STI Optronics, Inc., Bellevue, WA \\ M. Babzien, I. Ben-Zvi, J. C. Gallardo, K. P. Kusche, I. V. Pogorelsky, J. Skaritka, A. van \\ Steenbergen, V. Yakimenko, BNL, Upton, NY \\ D. B. Cline, P. He, Y. Liu, UCLA, Los Angeles, CA \\ R. B. Fiorito, Catholic University of America, Washington, DC \\ R. H. Pantell, Stanford University, Stanford, CA \\ D. W. Rule, Naval Surface Warfare Center, West Bethesda, MD \\ J. Sandweiss, Yale University, New Haven, CT
}

\section{Abstract}

Progress is reported on the Staged Electron Laser Acceleration (STELLA) experiment, which has been assembled on the BNL Accele:ator Test Facility (ATF). The primary goal of STELLA is to demonstrate staging of the laser acceleration process by using the BNL inverse free electron laser (IFEL) as a prebuncher, which generates $\sim 1-\mu \mathrm{m}$ long microbunches, and accelerating these microbunches using an inverse Cerenkov acceleration (ICA) stage. Experimental runs are underway to recommission the IFEL and ICA systems separately, and reestablish the microbunching process. Staging will then be examined by running both the IFEL and ICA systems together.

\section{INTRODUCTION}

The primary goal of the Staged Electron Laser Acceleration (STELLA) Experiment, located at the BNL Accelerator Test Facility (ATF), is to demonstrate laser acceleration of optically preburiched microbunches [1-2]. Specifically, the BNL inverse free electron laser (IFEL) [3] will be used to prebunch the electrons into a bunch length of $\sim 1 \mu \mathrm{m}$. The STI inverse Cerenkov accelerator (ICA) [4] will be used to accelerate these microbunches. Critical issues that will be addressed during this experiment include proper rephasing of the microbunches with the $10-\mu \mathrm{m}$ laser beam wave inside the ICA gas cell. The basic layout for the experiment is depicted in Fig. 1.

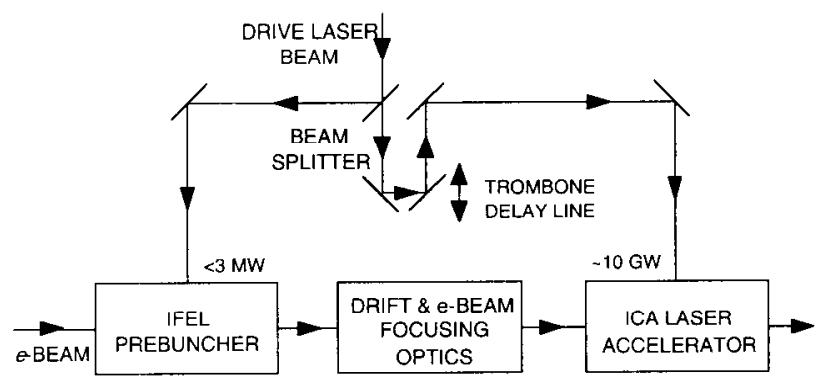

Figure 1: Conceptual layout STELLA experiment.

The experiment is nearly fully assembled at the ATF and is currently undergoing recommissioning of the primary system components. This paper describes the progress to date.

\section{DESCRIPTION OF EXPERIMENT}

\subsection{Electron Beamline}

Figure 2 is a drawing of Beamline \#1 at the ATF where the STELLA experiment is located. The electrons enter

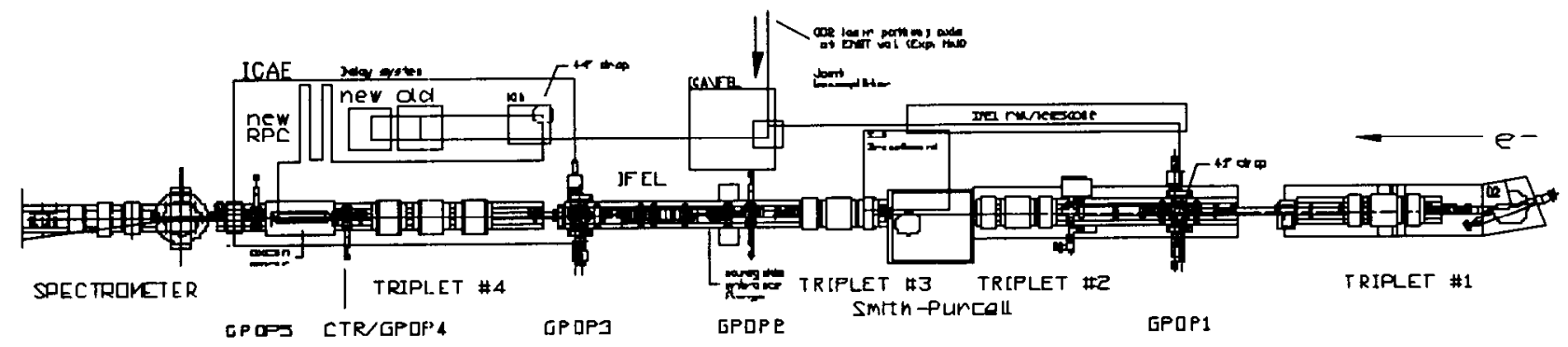

Figure 2: Layout of STELLA beamline.

\footnotetext{
'Work supported by U.S. Department of Energy, Grant Nos. DE-FG03-98ER41061, DE-AC02-98CH10886, and DE-FG03-92ER40695.

"Email: wkimura@stioptronics.com
} 
from the right. There are three locations along the beamline where the $e$-beam must be focused to small sizes. The first is a turning mirror with a $3-\mathrm{mm}$ dia. central hole located inside the beamline at GPOP1. This mirror is used to direct the ATF psec $\mathrm{CO}_{2}$ laser beam [5] into the IFEL wiggler. The second constraint is the 60$\mathrm{cm}$ long sapphire waveguide with an internal diameter of $2.8 \mathrm{~mm}$, which is used to channel the laser radiation through the IFEL wiggler [3]. The third constraining location is within the ICA gas cell where the $e$-beam needs to be focused to $<100 \mu \mathrm{m}$ for optimum spatial overlap with the focused laser beam inside the ICA acceleration region. Triplets along the beamline are used to focus the $e$-beam through these various constraint points.

\subsection{Prebuncher (IFEL)}

Details of the IFEL design are in Ref. 3. The wiggler parameter values for STELLA are listed in Table 1.

Table 1: IFEL wiggler parameters for STELLA.

\begin{tabular}{|l|c|}
\hline \multicolumn{1}{|c|}{ Parameter } & Design Value \\
\hline Wiggler length & $47 \mathrm{~cm}$ \\
\hline Wiggler period & $3.3 \mathrm{~cm}$ (untapered) \\
\hline Wiggler gap & $0.4 \mathrm{~cm}$ \\
\hline$K$ parameter & 2.86 for $45 \mathrm{MeV} e$-beam \\
\hline On axis peak field & $0.927 \mathrm{~T}$ (based on $K$ value) \\
\hline
\end{tabular}

Unlike the previous IFEL demonstration discussed in Ref. 3, which used a tapered wiggler, the purpose of the IFEL for the STELLA experiment is not to impart large energy gains onto the beam. Rather only a modest amount of energy modulation $( \pm 0.55 \%)$ is necessary to cause optimum microbunching to occur at the ICA gas cell located $2 \mathrm{~m}$ downstream from the IFEL. This implies only relatively low laser power is needed to drive the IFEL. This is one of the reasons for choosing a uniform wiggler. The performance of an untapered wiggler is also more tolerant of variations in the $e$-beam and laser beam parameters.

\subsection{Laser Accelerator (ICA)}

Reference 4 contains more explanation about the ICA system. The gas cell is designed to use a $20 \mathrm{mrad}$ Cerenkov angle. Hydrogen gas is used as the phase matching medium at a pressure of $\sim 2 \mathrm{~atm}$. In order to minimize the effects of gas and window scattering, which can degrade the trapping process, the interaction length inside the cell is $6.5 \mathrm{~cm}$. New, thinner $1-\mu \mathrm{m}$ thick diamond windows for the $e$-beam will be used at the entrance and exit to the cell.

An important issue during the experiment is spatially overlapping the $e$-beam and laser beam inside the cell. When focused by the axicon [4] onto the $e$-beam, the laser beam focal diameter will be $200 \mu \mathrm{m}$ FWHM. The central $100 \mu \mathrm{m}$ of this $200-\mu \mathrm{m}$ beam is relatively uniform in field. Hence, the $e$-beam, which will be focused to $<100 \mu \mathrm{m}$, needs to propagate through this central $100-\mu \mathrm{m}$ width of the focused laser beam over the entire $6.5 \mathrm{~cm}$ interaction length.

A new type of beam position monitor (BPM), capable of detecting both the $e$-beam and laser beam with high resolution, will be used inside the gas cell in ensure the spatial overlap of the beams. This BPM consists of a 1$\mathrm{mm}$ thick, 2.54-cm dia. silicon wafer coated with a thin layer of oxidized vanadium $\left(\mathrm{VO}_{\mathrm{x}}\right)$ [6] that can be inserted perpendicular to the $e$-beam and laser beam propagation. A small mirror held below the centerline of the silicon wafer permits the face of the $\mathrm{VO}_{\mathrm{x}}$-coated side of the wafer to be viewed from above using a camera with a macro-zoom lens.

A photograph of the wafer/mirror system is given in Fig. 3. This BPM is designed to be remotely inserted onto the beam axis using electrical solenoids. Two of these BPMs will be used inside the gas cell near the beginning and end of the interaction region.

The $\mathrm{VO}_{x}$, when heated to a temperature of $\sim 50^{\circ} \mathrm{C}$, changes its reflectivity when the $\mathrm{CO}_{2}$ laser beam is focused onto it. The extremely fine grain size of the $\mathrm{VO}_{\mathrm{x}}$ permits features $<1 \mu \mathrm{m}$ to be resolved. (In this system the resolution is limited to $\sim 10 \mu \mathrm{m}$ by the camera/lens system.) A Nichrome wire in the shape of a single loop is pressed against the outer edge of the wafer by sandwiching the wafer and wire between two Teflon rings (see Fig. 3). This wire is used to heat the wafer. Another attractive feature of this BPM is that the image on the $\mathrm{VO}_{\mathrm{x}}$ remains after exposure to the laser light as long as the wafer is kept heated. This image can be erased by allowing the wafer to cool.

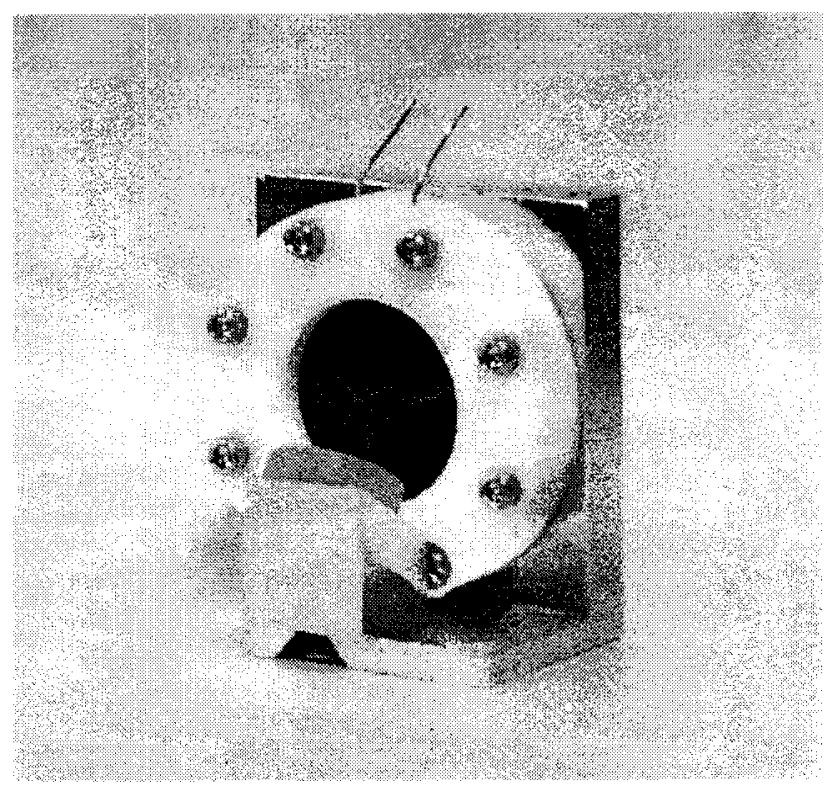

Figure 3: Photograph of oxidized vanadium BPM. 
A miniature RTD temperature sensor (not shown in Fig. 3) is attached to the surface of the wafer to permit remote monitoring of the surface temperature.

The $e$-beam position is determined by observing the optical transition radiation (OTR) generated when the $e$ beam passes through the silicon wafer.

\subsection{Diagnostics}

Two diagnostics are critical for the experiment. The first is a new spectrometer installed at the end of the beamline. Details of this new device can be found in Ref. 7. It features a very broad energy acceptance range $( \pm 20 \%)$. This is necessary because of the large acceleration/deceleration $(\sim \pm 10 \mathrm{MeV})$ that can be imparted by the ICA cell. (The first experiments will be intentionally performed at much lower energy gains.) Since initially the accclcrated microbunch will be located anywhere within this energy range, it is important to observe the entire energy spectrum at once so that the proper phase adjustment can be made to accelerate the microbunch.

The second important diagnostic is for detecting the presence of the microbunches generated by the IFEL using coherent transition radiation (CTR) [8]. This detector is located just beforc the ICA cell where maximum bunching is needed. By monitoring the CTR signal, the laser power to the IFEL can be adjusted to obtain optimum bunching at the gas cell. The CTR diagnostic used in STELLA is essentially a stationary position version of the one described in Ref. 8. It also uses a thinner $6.4-\mu \mathrm{m}$ thick AI foil as the CTR target. This foil together with a ighter $e$-beam focusing capability should significantly increase the CTR signal.

\section{RECENT EXPERIMENTAL RESULTS}

At the time of the writing of this paper, recommissioning of the IFEL and CTR diagnostic is in progress using the new spectrometer. Table 2 lists the basic parameters for the experiment during the most recent runs.

Table 2: Experimental parameters during recent recommissioning runs.

\begin{tabular}{|l|c|}
\hline \multicolumn{1}{|c|}{ Parameter } & $\begin{array}{c}\text { Value during recent } \\
\text { runs }\end{array}$ \\
\hline Electron beam energy & $\sim 45 \mathrm{MeV}$ \\
\hline $\begin{array}{l}\text { Beam charge at end of } \\
\text { line }\end{array}$ & $\sim 250 \mathrm{pC}$ \\
\hline Laser power to IFEL & $\sim 200 \mathrm{MW}$ \\
\hline E-beam focus at CTR & $\sigma \sim 100-200 \mu \mathrm{m}$ \\
\hline
\end{tabular}

For a delivered laser power to the IFEL of $-200 \mathrm{MW}$, a normalized $e$-beam energy modulation of $\pm 0.42 \%$ was measured. This value is close to the $\pm 0.55 \%$ modulation needed to achieve optimum bunching $2-m$ downstream from the wiggler. (The higher than expected laser power required to achieve this level of modulation may be due to system inefficiencies, which should be reduced as the system undergoes further fine tuning and testing.)

During these initial CTR tests the IR detector sensed wavelengths shorter than $5 \mu \mathrm{m}$. (Recall microbunching should cause enhanced CTR signals at the higher harmonics of the laser beam.) A CTR signal was detected and correlated with the presence of the laser beam in the IFEL. This initial signal was roughly 10 times stronger than those obtained in Ref. 8, which affirms the design improvements made with this new diagnostic.

\section{FUTURE PLANS}

Recommissioning of the ICA system will occur next where enmphasis will be placed on generating a radially polarized laser beam with a minimum of imperfections and minimum beam divergence. It has been shown through modeling investigations that beam imperfections and divergence can degrade the ICA process [9].

After this the IFEL and ICA systems will be operated together and the first staging experiments will commence. Initially only modest acceleration will be attempted as the proper phasing and overlap conditions are found. Later, the laser power to the ICA cell will be increased to demonstrate higher energy gain.

\section{REFERENCES}

[1] W. D. Kimura, M. Babzien, I. Ben-Zvi, L. P. Campbell, D. B. Cline, R. B. Fiorito, J. C. Gallardo, S. C. Gottschalk, P. He, K. P. Kusche, Y. Liu, R. H. Pantell, I. V. Pogorelsky, D. C. Quimby, K. E. Robinson, D. W. Rule, J. Sandweiss, J. Skaritka, A. van Steenbergen, L.C. Steinhauer, and V. Yakimenko, "STELLA Experiment: Design and Model Predictions," in Proceedings of 8th Workshop on Advanced Accelerator Concepts, Baltimore, MD. Jul 5-11, 1998 .

[2] K. P. Kusche, M. Babzien, I. Ben-Zvi, L. P. Campbell, D. B. Cline, R. B. Fiorito, J. C. Gallardo, S. C. Gottschalk, P. He, W. D. Kimura, Y. Liu, R. H. Pantell, I. V. Pogorelsky, D. C. Quimby, K. E. Robinson, D. W. Rule, J. Sandweiss, J. Skaritka, A. van Steenbergen, L.C. Steinhauer, and V. Yakimenko, "STELLA Experinlent: Hardware Issues," in Proceedings of 8ht Work shop on Advanced Accelerator Concepts, Baltimore, MD, Jul. 5-11, 1998.

[3] A. van Steenbergen, J. Gallardo, J. Sandweiss, J-M. Fang, M. Babzien, X. Qiu, J. Skaritka, and X-J. Wang, Phys. Rev. Lett., 77. 2690 (1996).

[4] W. D. Kimura, G. H. Kim, R. D. Romea, L. C. Steinhauer, I. V. Pogorelsky, K. P. Kusche, R. C. Fernow, X. Wang, and Y. Liu, Phys. Rev. Lett. 74, 546-549 (1995).

[5] I. Pogorelsky, I. Ben-Zvi, W. D. Kimura, N. A. Kurnit, and F. Kannari, Infrared Phys. Tech. 36, 341 (1995).

[6] Oxidized vanadium coating provided by Optoel Corporation,

[7] http://www.nsls.bnl.gov/AccTest/Beam_Lines/linelspectr.htm

[8] Y. Liu, X-J. Wang, D. B. Cline, M. Babzien, J-M. Fang, J. Gallardo, K. Kusche, I. Pogorelsky, J. Skaritka, and A. van Steenbergen, Phys. Rev. Lett., 80, 4418 (1998).

[9] L. P. Campbell, W. D. Kimura, and V. Heyfitch, "Inverse Cerenkov Acceleration Modeling Using a Realistic Laser Beam," in preparation. 